\section{REVIEW} ARTICLE

\title{
Polyadenylation of mRNA in bacteria
}

\author{
Nilima Sarkar \\ Tel: +1 6177422010 ext. 353. Fax: +1 617523 6649. e-mail: sarkar@bbri.harvard.edu
}

Boston Biomedical Research Institute, 20 Staniford Street, Boston, MA 02114, and Department of Biological Chemistry and Molecular Pharmacology, Harvard Medical School, Boston, MA 02115, USA

Keywords: poly(A) polymerase, RNA synthesis, RNA degradation, $3^{\prime}$-exonucleases, $p c n B$

\section{Overview}

The presence of polyadenylate sequences at the 3 -end of mRNA was first observed in eukaryotic cells about 25 years ago (Darnell et al., 1971; Edmonds et al., 1971; Lee et al., 1971) and is now recognized as a characteristic feature of eukaryotic mRNAs other than those encoding the histones (Marzluff \& Pandey, 1988). Until recently, it was generally accepted that the 3 -polyadenylation of mRNA is a eukaryotic feature and does not occur to a significant extent in prokaryotes. This view persisted in spite of numerous reports on bacterial polyriboadenylate [poly(A)] RNA over almost a 20 -year period. There were several reasons for this scepticism: (i) the lack of success of early efforts to detect poly(A) RNA in bacterial cells (Edmonds et al., 1971; Perry et al., 1972), (ii) the difficulty of studying a labile segment of the already very shortlived bacterial mRNA, especially at a time when the methodology available for studying mRNA was still quite primitive, (iii) the relatively short length of the bacterial poly(A) and the apparently limited extent of mRNA polyadenylation, which cast doubt on its physiological significance, and (iv) the difficulty of rationalizing a role for the 3'-terminal modification of bacterial mRNA in organisms where transcription and translation are usually closely coupled. This review presents the accumulated evidence for the extensive 3 '-polyadenylation of bacterial mRNA and for a complex enzymic machinery that determines the level of mRNA polyadenylation. The functional role of bacterial polyadenylation remains unclear and may include the modulation of mRNA stability. Other possibilities, such as a role in translation analogous to that recently proposed for eukaryotic mRNAs (Sachs, 1990; Sachs \& Deardorff, 1992) have not yet been explored.

\section{Detection of poly(A) RNA in bacteria}

As early as 1975, three separate groups of researchers described low levels of poly(A) RNA in bacteria. Examining the RNA from the Gram-negative bacterium Caulobacter crescentus by poly(U) filter binding, Newton and his co-workers (Ohta et al., 1975) reported that $7 \%$ of rapidly turning-over mRNA contained poly(A) tracts ranging from 15 to 50 residues in length. Almost simultaneously, Edmonds and co-workers (Nakazato et al., 1975) described the occurrence of low levels $(0.2 \%)$ of poly(A) RNA in pulse-labelled RNA of Escherichia coli, with 3'-terminal poly(A) tracts 25-50 residues long. In the same year, Srinivasan et al. (1975), using E. coli grown in low-phosphate medium, extracted pulse-labelled RNA [in the presence of high salt to inhibit poly(A)-degrading enzymes] and showed as much as $15 \%$ of pulse-labelled RNA to be polyadenylated. Although the studies from these three laboratories were biochemically convincing, they had little impact on the prevailing view that polyadenylation of bacterial mRNA was of no physiological significance.

Yet at the same time, an indication that bacterial RNA polyadenylation is physiologically significant emerged from studies on RNA synthesis in permeabilized cells of Bacillus brevis, where the degradation of newly synthesized RNA is primarily due to the action of a $3^{\prime}$-exonuclease that is inhibited by guanosine $3^{\prime}, 5^{\prime}$-monophosphate (Paulus \& Sarkar, 1974; Sarkar \& Paulus, 1975). This 3'exonuclease acts much more slowly on poly $(A)$ than on other polynucleotides, suggesting that the stability of bacterial mRNA might be modulated by polyadenylation. To explore this possibility, a one-step procedure for the isolation of bacterial poly(A) RNA was developed, which involved lysis of pulse-labelled cells and immediate digestion by proteinase $\mathrm{K}$ in the presence of SDS, 1,10phenanthroline and heparin, to degrade or inhibit $3^{\prime}$ exonucleases (Gopalakrishna et al., 1981). Pulse-labelled RNA isolated by this procedure from B. brevis (Sarkar $e t$ al., 1978; Gopalakrishna \& Sarkar, 1982a), as well as from Bacillus subtilis and E. coli B (Gopalakrishna et al., 1981), had a relatively high degree of polyadenylation $(15-40 \%)$. It seems that earlier reports of very low levels of poly(A) RNA $(0.1-0.3 \%)$ in the budding bacterium Hyphomicrobium sp. B522 (Kaur \& Jayaraman, 1979), and the absence of poly(A) RNA from vegetative cells of $B$. subtilis (Schultz et al., 1978) and Bacillus polymyxa (Kaur \& Jayaraman, 1979), could be attributed to the use of 
isolation procedures which promoted the degradation of poly(A) RNA by cellular nucleases. Indeed, later studies using the RNA isolation method of Gopalakrishna $e t$ al. (1981) revealed high levels of poly(A) RNA (16\%) in the archaeon Methanococcus vannielii (Brown \& Reeve, 1985) and even higher levels $(20-50 \%)$ in the protein-secreting B. brevis 47 (Hussain et al., 1982). The proportion of poly(A) RNA in total unlabelled RNA at steady state was estimated in B. subtilis by the formation of ribonucleaseresistant hybrids with $\left[{ }^{3} \mathrm{H}\right]$ poly $(\mathrm{U})$ as $2-3 \%$ of the total cellular RNA, which corresponds to about $50 \%$ of the steady-state level of mRNA (Gopalakrishna \& Sarkar, 1982a).

\section{Characterization of poly(A) RNA from bacteria}

In most of the studies cited above, isolation of poly(A) RNA was achieved by affinity chromatography of RNA on oligo(deoxythymidylate) [oligo(dT)]-cellulose or poly(U)-Sepharose (Srinivasan et al., 1975; Sarkar et al., 1978; Hussain et al., 1982; Gopalakrishna \& Sarkar, 1982a; Brown \& Reeve, 1985). These studies also showed that poly(A) is associated with pulse-labelled RNA, presumably mRNA, whereas long-term-labelled cellular RNA contains a very low level of poly(A) RNA. Susceptibility of the poly(A) tracts to preferential degradation by snake-venom phosphodiesterase indicated that they are primarily located near the 3 '-ends of the RNA molecules (Sarkar et al., 1978; Hussain et al., 1982; Gopalakrishna \& Sarkar, 1982a; Majumdar \& McFadden, 1984). The mean length of the poly(A) tracts, isolated by digesting poly(A) RNA with ribonucleases $A$ and T1, was estimated from their electrophoretic mobility in polyacrylamide gels and the adenosine:AMP ratio after alkaline hydrolysis, and was found to vary widely amongst bacteria: 13-17 nucleotides in Caulobacter crescentus (Ohta et al., 1978), 10-50 nucleotides in E. coli (Nakazato et al., 1975), 60 nucleotides in B. brevis (Sarkar et al., 1978), 49 nucleotides in B. subtilis (Gopalakrishna \& Sarkar, 1982a), 10 nucleotides in the archeon $M$. vanniellii (Brown \& Reeve, 1985), and 80 nucleotides in the photosynthetic bacterium Rhodospirillum rubrum (Majumdar \& McFadden, 1984). The bacterial poly(A) tracts are thus considerably shorter than the poly(A) tracts associated with $\mathrm{mRNA}$ in higher eukaryotes but are in approximately the same size range as those from yeast (McLaughlin et al., 1973).

Sedimentation analysis and polyacrylamide gel analysis of pulse-labelled poly(A) RNA showed a polydisperse pattern ranging from $4 \mathrm{~S}$ to $16 \mathrm{~S}$ in E. coli (Nakazato et al., 1975) and C. crescentus (Ohta et al., 1975). The weight mean sedimentation coefficient of $B$. brevis poly(A) RNA was $12.5 \mathrm{~S}$, corresponding to a mean length of $800-900$ nucleotides (Sarkar et al., 1978). This is a typical size range for mRNA ; indeed, a significant amount of poly(A) RNA in C. crescentus (Ohta et al., 1978) and B. brevis (Käufer et al., 1981) was found to be associated with polysomes. Further evidence that poly(A) RNA is mainly mRNA comes from measuring its ability to serve as a template for in vitro protein synthesis. Poly(A) RNA from B. subtilis was 20-fold more effective than non-poly(A) RNA in stimulating the incorporation of radioactive amino acids in a cell-free system derived from $E$. coli MZ9 (Gopalakrishna \& Sarkar, 1982a). Using a cell-free protein synthesis from wheat germ, Majumdar \& McFadden (1984) observed an even more impressive stimulation of amino acid incorporation by poly(A) RNA from $R$. rubrum (220-fold compared to non-poly(A) RNA) and were able to show by the use of specific antibodies that one of the major products was ribulosebisphosphate carboxylase/oxygenase. Additional evidence for translational activity of poly(A) RNA came from the high translational activity of poly(A)-RNA-containing polysomes from $B$. brevis in the presence of soluble factors (Käufer et al., 1981).

In view of the evidence that poly(A) RNA is primarily mRNA, it was of interest to determine whether polyadenylated mRNA functioned only in certain physiological contexts. To address the possibility of a specific function during developmental transitions, the levels of poly(A) RNA were compared during vegetative growth and sporulation of Bacillus species, but no significant differences in the poly(A) RNA content in pulse-labelled RNA were found either with B. brevis (Gopalakrishna et al., 1981) or with B. subtilis (Gopalakrishna \& Sarkar, 1982a). Earlier reports that poly(A) RNA was present only in sporulating cells of B. polymyxa (Kaur \& Jayaraman, 1979) and B. subtilis (Kerjan \& Szulmajster, 1980) have not been confirmed. Similarly, poly(A) RNA was found to be present at all stages of growth and development of $C$. crescentus (Ohta et al., 1978).

The question of whether poly(A) RNA consists of a restricted subpopulation of $m R N A$ molecules or whether it comprises most mRNA sequences was addressed by comparing sequence complexity of poly(A) RNA and non-poly(A) RNA by hybridization to Southern blots of EcoRI-digested B. subtilis DNA. Complex hybridization patterns were observed with both types of RNA, but no bands could be identified as unique to non-poly(A), consistent with the idea that poly(A) RNA comprises most mRNA species (Gopalakrishna \& Sarkar, 1982a). Independent confirmation that a broad range of bacterial $\mathrm{mRNAs}$ is polyadenylated was obtained by the oligo(dT)primed synthesis of complementary DNA (cDNA) by reverse transcriptase. With purified poly(A) RNA from $B$. subtilis as template, the mean chain-length of the cDNA was 400 nucleotides, with a range from 230 to 800 (Gopalakrishna \& Sarkar, 1982b). Moreover, the cDNA thus synthesized could serve as template for doublestranded cDNA synthesis, making possible its insertion into plasmids such as pBR322 and subsequent cloning in E. coli, to yield a cDNA library (Karnik et al., 1986). Six clones from the first such cDNA library (400 clones) were sequenced and found to carry at the 3 -end of the sense strand runs of deoxyadenylate residues ranging from 4 to 19 , preceded by at least one translation termination codon in one of the possible reading frames. It should be noted that the length of the poly $(\mathrm{dA})$ tracts in the cDNA does not necessarily reflect the poly(A) length in the corresponding mRNA, but rather that of the oligo(dT) 
primers used in cDNA synthesis, and may have been shortened as a result of the extensive $\$ 1$ nuclease treatment that was needed to allow the cloning of double-stranded cDNA. The demonstration that cDNA libraries can be constructed from bacterial mRNA (Karnik et al., 1986) provides a valuable tool for future studies of bacterial transcription patterns.

\section{Identification of specific polyadenylated MRNAs in E. coli}

One of the reasons for the relatively slow acceptance of the notion that polyadenylation of bacterial $m R N A$ is a process of physiological significance may have been the fact that many of the earlier studies on poly(A) RNA were done in bacterial species that were biochemically and genetically less well-characterized than E. coli. There was therefore an important need to initiate studies of mRNA polyadenylation in E. coli on the molecular level. For this purpose, we chose two of the biochemically and genetically best-characterized E. coli mRNAs as subjects for the study of mRNA polyadenylation: the outermembrane lipoprotein mRNA (Taljanidisz et al., 1987), encoded by $l p p$, and the mRNA for the $\alpha$-subunit of tryptophan synthase (Karnik et al., 1987), encoded by $\operatorname{tr} p A$. lpp is expressed constitutively to produce the most abundant and one of the most stable mRNAs in E. coli and its product is a structural protein that is secreted through the cytoplasmic membrane. $\operatorname{tr} p A$, on the other hand, is part of a polycistronic biosynthetic operon under repressor and transcription attenuation control and has the short half-life typical of most $E$. coli mRNAs. These specific mRNAs, expressed from plasmids, were characterized by (i) their ability to bind to oligo(dT)-cellulose and the loss of that ability by treatment with RNase $\mathrm{H}$ and oligo(dT), (ii) the isolation and sizing of the poly(A) tracts after digestion with RNase $A$ and $T_{1}$, and (iii) their ability to serve as templates for the oligo(dT)-dependent synthesis of cDNA by reverse transcriptase. Parallel studies were carried out on newly synthesized mRNA identified by in vivo pulse-labelling, on the steady state mRNA population, isolated by hybrid selection with specific probes, followed by $3^{\prime}$-end labelling, and on RNA synthesized in permeable cells, described in the next section. The results obtained with $l p p$ mRNA (Taljanidisz et al., 1987) and with $\operatorname{trp} A \mathrm{mRNA}$ (Karnik et al., 1987) are summarized in Table 1.
Taking advantage of the elevated levels of poly(A) RNA in E. coli pnp $r n b$ mutant strains (see below), DNA complementary to polyadenylated lipoprotein mRNA, encoded by the $l p p$ gene, was successfully synthesized using avian myeloblastosis virus reverse transcriptase and an oligo(dT)-containing primer. By amplifying the cDNA by PCR and appropriate oligonucleotide primers, it was possible to clone the DNA complementary to the $3^{\prime}$-end of $l p p$ mRNA in pUC18 and to determine its sequence (Cao \& Sarkar, 1992a). Four clones containing the Cterminal coding region of $l p p$ mRNA were obtained and were found to contain poly $(A)$ tracts at either of two sites in the $3^{\prime}$-terminal untranslated region of the transcript, suggesting that there are at least two classes of polyadenylated transcripts (Fig. 1). In class I transcripts, the polyadenylate tract is attached at the putative $\rho$-independent transcription termination site of $l p p$ mRNA (Nakamura et al., 1980), whereas in class II transcripts, the polyadenylate moiety is attached to the residue just preceding the terminal stem-loop of the primary transcript (Nakamura et al., 1980), thus replacing the $\rho$ independent transcription terminator (Cao \& Sarkar, 1992a). The possibility that class II polyadenylated cDNA are an artefact produced by oligo(dT) priming at the A-rich region at the base of the terminal stem-loop is ruled out by the observation that the length of many of the cloned $\operatorname{poly}(\mathrm{A})$ tracts exceed the length of the oligo(dT) primers (Cao \& Sarkar, 1992a, 1993). An important implication of this work, which represented the first molecular description of a bacterial poly(A) RNA, is that mRNA polyadenylation is not necessarily coupled directly to transcription termination, but may occur post-transcriptionally as one of a complex set of mRNA-processing events, which also include endonucleolytic and exonucleolytic cleavage reactions (Cao \& Sarkar, 1992a). More recently, the site of polyadenylation of another $E$. coli $\mathrm{mRNA}, r p s \mathrm{O}$ m NA encoding ribosomal protein $\mathrm{S} 15$, was elucidated using a similar approach, except that the $E$. coli strain used was also deficient in the endonuclease RNase E, encoded by rne (Hajnsdorf et al., 1995). Of 33 cDNA clones analysed, 32 were of class I (Hajnsdorf $e t$ al., 1995). The absence of class II poly(A) RNAs in this case is not surprising since the $E$. coli strain that served as the source of mRNA was deficient in RNase E, the enzyme thought to be responsible for endonucleolytic cleavage just upstream of the stem-loop of the $\rho$-independent terminator structure. In contrast, Hajnsdorf et al. (1995)

Table 1. Degree of polyadenylation of $E$. coli trpA mRNA and Ipp mRNA

\begin{tabular}{|lccccc|}
\hline $\begin{array}{l}\text { Type of RNA } \\
\text { analysed }\end{array}$ & $\begin{array}{c}\text { Percentage } \\
\text { polyadenylated }\end{array}$ & $\begin{array}{c}\text { Length of } \\
\text { poly(A) tract } \\
\text { (nt) }\end{array}$ & & $\begin{array}{c}\text { Percentage } \\
\text { polyadenylated }\end{array}$ & $\begin{array}{c}\text { Length of } \\
\text { poly(A) tract } \\
\text { (nt) }\end{array}$ \\
\hline Steady state & 36 & & 9 & 47 & 9 \\
Newly synthesized & 48 & $15-20$ & & 42 & $10-15$ \\
In vitro synthesized & 45 & 14 & 50 & 15 \\
\hline
\end{tabular}




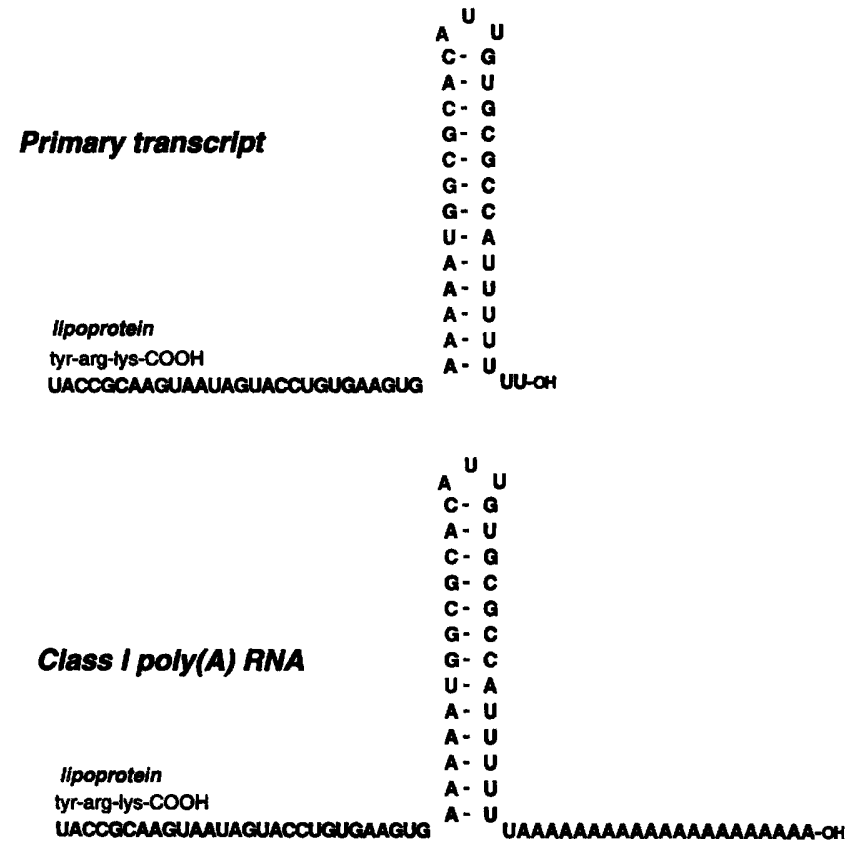

Class II poly(A) RNA

IIpoprotein

tyr-arg-lys-COOH

UACCCCAMCUAAUAGUACCUGUGAARAMAMARAAMAAAMAMAMA-O

Fig. 1. Comparison of the 3'-terminal portion of two classes of polyadenylated Ipp mRNA molecules found with the primary Ipp transcript determined by Inouye and co-workers (Nakamura et al., 1980).

found one unusual cDNA in which a 63 nucleotide poly(A) tract was attached to a site within the $r p s \mathrm{O}$ coding region. Whether this clone reflects a third class of poly(A) RNA, produced by the polyadenylation of $\mathrm{mRNA}$ degradation products, remains to be determined.

The complementary DNA approach has also been applied to the elucidation of the molecular structure of poly(A) RNA in B. subtilis, except that, owing to the intrinsically higher levels of poly(A) RNA in Bacillus species, the need for using exonuclease-deficient strains could be avoided. The 3 -terminal sequence of polyadenylated flagellin mRNA, encoded by the $B$. subtilis bag gene, was found to contain only one polyadenylation site, just upstream of the putative $\rho$-independent transcription terminator (CaO \& Sarkar, 1992a), corresponding to the E. coli class II poly(A) RNA. With only one B. subtilis poly(A) RNA cloned at this time, it is not possible to address the question whether all $B$. subtilis poly(A) RNAs are of the class II type.

\section{Relationship between polyadenylation and nucleolytic cleavage at the 3 '-ends of mRNA}

The identification of two classes of polyadenylated $l p p$ mRNA, one in which the poly(A) moiety is attached to the stem-loop structure at the end of the primary $l p p$ transcript (class I) and a second in which the $3^{\prime}$-terminal stem-loop structure is lacking (class II), suggests that the terminal processing of bacterial mRNA involves competition between polyadenylation and nucleolytic degradation (Cao \& Sarkar, 1992a, b), as illustrated in Fig. 2. In E. coli, the primary transcript can be either polyadenylated at its $3^{\prime}$ end or degraded by $3^{\prime}$-exonucleases, even though the latter process would be expected to be retarded by the terminal stem-loop structure (McLaren et al., 1991; Coburn \& Mackie, 1996). The polyadenylated transcript, no longer terminated by a stem-loop, will be more susceptible to $3^{\prime}$-exonuclease degradation than the primary transcript, and RNase II, polynucleotide phosphorylase (PNPase), and poly(A) polymerase (PAP) will actively compete for its $3^{\prime}$-end. However, the primary transcript (as well as its polyadenylation product) can also be cleaved by RNase $\mathrm{E}$ at a specific site at the base of the terminal stem-loop structure, as demonstrated both in vivo and in vitro for $r p s O \mathrm{mRNA}$ (Régnier \& Hajnsdorf, 1991). RNase $E$ has been implicated in the control of $m R N A$ stability (Ono \& Kuwano, 1979; Arraiano et al., 1988; Ehretsmann et al., 1992). The cleaved transcript, no longer protected from 3 '-exonucleolytic degradation by the terminal secondary structure, would be highly vulnerable to degradation by $3^{\prime}$-exonucleases such as PNPase or RNase II and, again, competition will ensue between degradation and polyadenylation. The postulated competition between exonucleases and PAP is consistent with the observation that strains of $E$. coli lacking the two exonucleases have higher cellular concentrations of polyadenylated mRNA (Cao \& Sarkar, 1992a). In wild-type strains of E. coli, all the reactions shown in the scheme would be operating simultaneously and in competition. In rne mutants, which are defective in ribonuclease $\mathrm{E}$, only the top portion of the scheme in Fig. 2 would be operating. In such a situation, only class I poly(A) RNA would be obtained, as was indeed observed with $r p s O \mathrm{mRNA}$ (Hajnsdorf et al., 1995).

Relatively little is known about the enzymology of mRNA turnover in Bacillus species. Deutscher \& Reuven (1991) compared the relative rates of phosphorolysis and hydrolysis of poly(A) in extracts of $B$. subtilis and E. coli and found phosphorolysis to predominate in the former, consistent with earlier in vivo labelling studies with $\mathrm{H}_{2}{ }^{18} \mathrm{O}$ suggesting that mRNA turnover is primarily phosphorolytic in B. subtilis (Duffy et al., 1972) and hydrolytic in $E$. coli (Chaney \& Boyer, 1972). In contrast, much smaller differences are seen between the rates of phosphorolysis and hydrolysis of poly(U) (Deutscher \& Reuven, 1991) and with in vivo-labelled total RNA (Wang \& Bechhofer, 1996), suggesting that the observed selectivity may be more a reflection of 3 -exonuclease specificities than of their relative activities. Indeed, the overall mRNA halflife in $B$. subtilis is relatively little affected by the deletion of $\operatorname{pnp} A$, the gene encoding PNPase, indicating the involvement of other $3^{\prime}$-exonucleases in mRNA turnover (Wang \& Bechhofer, 1996). A $\mathrm{K}^{+}$-dependent 3'exoribonuclease, sensitive to inhibition by $3^{\prime}, 5^{\prime}$ cyclicGMP, has been purified from B. brevis (Sarkar \& Paulus, 1975) and B. subtilis (Kerjan \& Szulmajster, 1976). The observations that this enzyme plays a major role in 


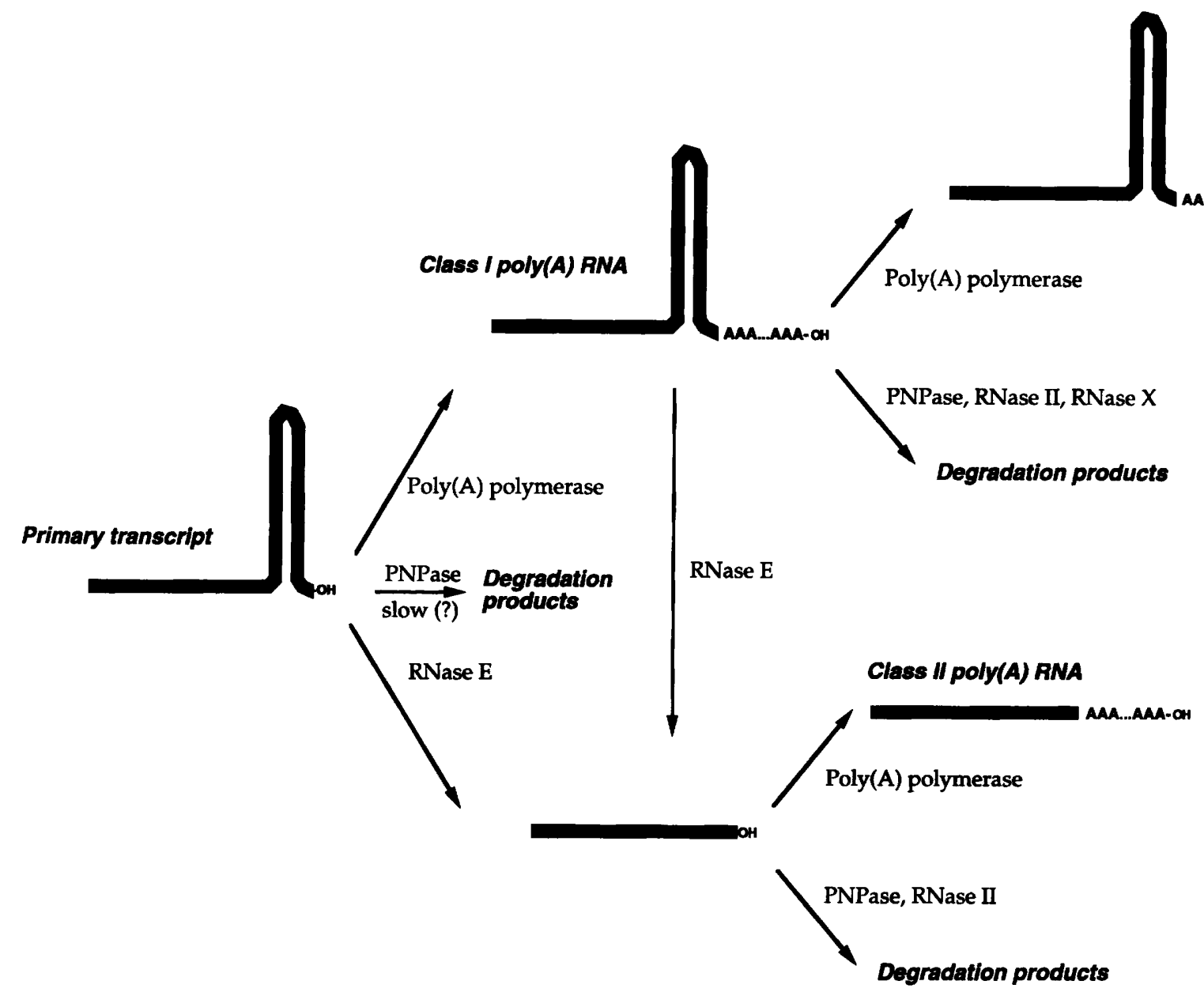

Fig. 2. Postulated steps in the processing of primary transcripts produced by rho-independent transcription termination. RNase $X$ refers to unknown 3'-exonucleases. See text for discussion.

the degradation of newly synthesized RNA in permeabilized cells of B. brevis (Sarkar \& Paulus, 1975), and that polyadenylated mRNA is relatively resistant to its action (Gopalakrishna \& Sarkar, 1981), suggests that the role of mRNA polyadenylation in $B$. brevis may primarily be protection against exonucleolytic degradation. Similar experiments have not yet been carried out in B. subtilis. Important questions that need to be addressed concern the role of the $3^{\prime}, 5^{\prime}$-GMP-sensitive exonuclease in mRNA degradation in $B$. subtilis and the identity of its natural allosteric ligand, $3^{\prime}, 5^{\prime}$-GMP not being found in Bacillus species at appreciable concentrations (Sarkar \& Paulus, 1975).

\section{Synthesis and polyadenylation of mRNA in permeabilized E. coli cells}

Cells of E. coli made permeable to nucleotides and other small molecules by treatment with toluene are capable of synthesizing poly(A) RNA from nucleoside triphosphate precursors, with $10-15 \%$ of the newly synthesized RNA being polyadenylated (Gopalakrishna \& Sarkar, 1983). The poly(A) tracts associated with the newly synthesized
RNA were similar in their general characteristics to those described earlier after pulse-labelling of growing $E$. coli cells (Nakazato et al., 1975). Moreover, it was possible to effect the synthesis of $l p p$ mRNA (Taljanidisz et al., 1987 ) and $\operatorname{trp} A$ mRNA (Karnik et al., 1987) by using permeable cells of $E$. coli transformed with a plasmid carrying the appropriate gene. Such permeable cell systems may be useful as the first step in defining the enzymology of mRNA polyadenylation, because they allow the study of polyadenylation of pre-existing $\mathrm{mRNAs}$ by carrying out the synthesis in the presence of the RNA polymerase inhibitors rifampicin or streptolydigin (G.-j. Cao \& N. Sarkar, unpublished results). A cell-free system for specific polyadenylation of mRNA has not yet been developed.

\section{PAPs from bacteria}

As early as 1962 , an enzyme that polymerizes adenylate residues on an RNA primer, PAP, was discovered and partially purified from E. coli (August et al., 1962). A number of other purification procedures which led to PAP preparation with different properties were described 
subsequently (Schäfer et al., 1972; Sippel, 1973; Ramanarayanan \& Srinivasan, 1976). The recent progress in the characterization of bacterial poly(A) RNA again focused attention on PAP as the source of the poly(A) moieties at the 3 -end of E. coli $\mathrm{mRNA}$. To evaluate the role of polyadenylation in bacteria, it was important to identify the gene encoding PAP. To this end, the major PAP (PAP I) of E. coli was purified and its 25 residue Nterminal amino acid sequence was used to design primers for the amplification of the corresponding coding region by PCR from an E. coli DNA template (Cao \& Sarkar, 1992b). A 74 bp DNA segment was obtained that matched a region in the $p c n B$ locus of $E$. coli, a gene that had originally been identified as controlling plasmid copynumber (Lopilato et al., 1986), and was subsequently cloned and sequenced (Liu \& Parkinson, 1989). Confirmation that the $p c n B$ locus encodes PAP was provided by the observation that a bacterial strain transformed with an inducible expression vector carrying $p c n B$ as a translational fusion produced 300 -fold elevated levels of PAP upon induction (Cao \& Sarkar, 1992b).

Sequence comparison of the deduced $\mathrm{PcnB}$ product with other proteins reveals a region with high similarity to a segment of E. coli tRNA nucleotidyltransferase (Masters et al., 1990) that may be an RNA binding site. The properties of purified E. coli PAP are similar to those reported for the eukaryotic enzyme involved in the polyadenylation of mRNA (Gershon et al., 1991; Lingner et al., 1991; Raabe et al., 1991; Wahle, 1991; Wahle et al., 1991): both enzymes are monomeric, have a strong tendency to aggregate under certain ionic conditions, have a $\mathrm{pH}$ optimum near $\mathrm{pH} 8$, require $\mathrm{Mg}^{2+}$ or $\mathrm{Mn}^{2+}$ for activity, and are relatively unspecific with respect to the primer for poly(A) synthesis. On the other hand, in spite of the many similarities in the properties of the PAPs from prokaryotes and eukaryotes, there is no obvious sequence similarity between the E. coli PAP and the corresponding enzymes from calf thymus (Raabe $e t$ al., 1991), vaccinia virus (Gershon et al., 1991) and yeast (Lingner et al., 1991).

The $p c n B$ gene encoding PAP is not essential for E. coli survival; indeed, mutants deleted for $p c n B$ show no consistent growth disadvantages (Liu \& Parkinson, 1989; Masters et al., 1993). Although the polyadenylation of $r p s O \mathrm{mRNA}$ was completely suppressed in $p c n \mathrm{~B}$ mutants (Hajnsdorf et al., 1995), the mean level of mRNA polyadenylation was reduced by less than $50 \%$ (Kalapos et al., 1994). This suggests the presence in $E$. coli of multiple PAPs with some functional overlap, a situation similar to that of the $3^{\prime}$-exonucleases (Kelly \& Deutscher, 1992; Reuven \& Deutscher, 1993a). E. coli deficient in both RNase II and PNPase are non-viable (Donovan \& Kushner, 1986) and it is possible that, analogously, E. coli deficient for a second poly(A)-polymerizing activity would suffer a growth disadvantage or even fail to survive. Indeed, a PAP activity that differs from the $p m n B$-encoded enzyme, was discovered in the course of studies of terminal adenylatetransferase activities in E. coli strains with a disrupted tRNA nucleotidyltransferase gene (Reuven \& Deutscher, 1993b). In a systematic search for additional PAPs in E. coli strains with a deletion of the $p c n B$ locus (Liu \& Parkinson, 1991), a second PAP (PAP II) was identified and purified about 1000-fold (Kalapos $e t$ al., 1994). While PAP I encoded by the $p c n B$ gene has a $M_{\mathrm{r}}$ of 53000 , PAP II is a smaller protein with a native $M_{\mathrm{r}}$ of $\sim 35000$; however, the properties of the two enzymes are similar, except that PAP II is more thermolabile and sensitive to salt concentrations (Kalapos et al., 1994). The gene for PAP II has recently been cloned and overexpressed as inclusion bodies, which on renaturation exhibit PAP activity (Cao et al., 1996). The relative contributions of PAP I and PAP II to mRNA metabolism of wild-type $E$. coli is of great interest and should be possible to define when deletion mutants of the gene encoding PAP II become available. Preliminary studies suggested that $E$. coli mutants lacking the genes encoding PAP I and PAP II are non-viable (Cao \& Sarkar, 1995).

Although PAPs have not been studied in other bacterial species, genes with significant homology to $E$. coli pcnB have been found in B. subtilis (A. V. Sorokin \& others, GenBank accession no. L47709), Mycobacterium leprae (E. DeRossi \& others, GenBank accession no. L39923) and Haemophilus influenzae (Fleischmann et al., 1995). It is interesting that the genome of the parasitic bacterium Mycoplasma genitalium (Fraser et al., 1995) lacks coding sequences homologous to PAPs or any of the known $E$. coli mRNA-degrading enzymes.

Very little is known about the mechanism of polyadenylation of bacterial mRNA. There is no evidence for a consensus sequence that serves as a polyadenylation signal. How bacterial PAPs achieve selectivity for mRNA while avoiding polyadenylation of rRNAs and tRNAs, how polyadenylation is coordinated with transcription termination, and how the desired length of $\operatorname{poly}(A)$ tail is achieved are all questions that have not yet been addressed.

\section{Possible roles of mRNA polyadenylation}

The role of mRNA polyadenylation has been difficult to define in molecular terms even in the eukaryotic field where this process has been known for 25 years. In bacteria, functional analysis is often facilitated by study of the phenotypic consequences of mutations affecting a process. Identification of $p c n B$ as the gene encoding PAP I has helped to define its function (Cao \& Sarkar, 1992b). $p c n B$ mutations were originally identified as host mutations that reduce the copy-number of ColE1-type plasmids (Lopilato et al., 1986), and thus polyadenylation by PAP I clearly has a role in regulating plasmid copynumber. Copy-number-control of ColE1 plasmids involves an antisense RNA (RNA I), which, by annealing to a primer RNA, prevents its use as a replication primer. An unrelated group of plasmids, IncFII, in which copynumber is also regulated, albeit differently, by an antisense RNA, also exhibits reduced copy-number in pcnB mutants (Masters et al., 1993). In the normal ColE1 replication cycle, RNA I is polyadenylated (Xu et al., 1993; Xu \& Cohen, 1995) and, after processing by RNase E, is rapidly degraded, with a half-life typical of mRNAs ( $\mathrm{He}$ et al., 
1993; Xu et al., 1993; Xu \& Cohen, 1995). In ponB mutants, the lack of polyadenylation leads to stabilization of RNA I after processing by RNase E, thus causing repression of plasmid replication (He et al., 1993; Xu et al., 1993; Xu \& Cohen, 1995). The degradation of RNA I is also much reduced in pnp mutants, suggesting that PNPase has a major role in the degradation of polyadenylated processed RNA I (Cohen, 1995; Xu \& Cohen, 1995). These studies indicate that one function of RNA polyadenylation may be to facilitate the rapid degradation of RNA molecules that terminate in a stem-loop structure by $3^{\prime}$-exonucleases such as PNPase (Cohen, 1995), which are known to be impeded by stem-loop structures (Guarneros \& Portier, 1990; McLaren et al., 1991).

Does PAP I have a role only in plasmid replication or also in host mRNA degradation? There is some evidence that poly(A) tracts do indeed destabilize certain types of mRNA. This includes the observation by $\mathrm{O}^{\prime}$ Hara et al. (1995) that the half-lives of $l p p, \operatorname{tr} x A$ and omp $A$ mRNAs are significantly increased by deletion of $p c n B$ when studied in a pnp rnb rne background. Similarly, $r p s O$ mRNA is stabilized by $p c n B$ deletions in a $p n p$ rnb rne background (Hajnsdorf et al., 1995). In both cases, mRNA stabilization was associated with a reduced level of polyadenylation. It should be noted that these results were obtained in the absence of RNase $\mathrm{E}$ and that the $3^{\prime}$-ends of most mRNAs therefore consist of the stem-loop structures of the $\rho$-independent transcription terminators, as shown in the top portion of Fig. 2. Since exonucleolytic degradation of RNA by PNPase and RNase II (Guarneros \& Portier, 1990; McLaren et al., 1991; Coburn \& Mackie, 1996) is strongly impeded by terminal stem-loop structures, polyadenylation of primary transcripts resulting from $\rho$-independent transcription termination would provide a 'toe-hold' for launching the processive exonucleolytic degradation by these enzymes (Cohen, 1995; Coburn \& Mackie, 1996) (Fig. 2).

However, the picture of RNA degradation at the $3^{\prime}$-ends of mRNA is far from complete. It must be noted that the effects of $p c n B$ deletions described in the preceding paragraph were observed only in rne mutants and not in a wild-type background and that mRNA destabilization by polyadenylation was much less pronounced (O'Hara et al., 1995) or absent (Hajnsdorf et al., 1995) in a wild-type background. Moreover, the observation that the absence of RNase II can stabilize transcripts (Hajnsdorf et al., 1994; Pepe et al., 1994; Py et al., 1996), the discovery of specific complexes involving RNase $\mathrm{E}$ and PNPase (Carpousis et al., 1994; Py et al., 1994), as well as the fact that mRNA degradation occurs efficiently even in the absence of RNase E, PNPase and RNase II (Hajnsdorf $e t$ al., 1995; O'Hara et al., 1995) suggests that additional factors must be taken into consideration before the roles of PAPs and ribonucleases in mRNA degradation can be fully understood.

Another major uncertainty concerns the relative roles of the two PAPs found in E. coli (Kalapos et al., 1994). The fact that deletion of the gene for PAP I, $p c n B$, is not lethal (Liu \& Parkinson, 1989; Masters et al., 1993) suggests that, if polyadenylation is an important function, there must be some functional overlap between PAP I and PAP II. However, it is clear that some functions are unique to PAP I, such as polyadenylation of the antisense RNAs involved in the control of plasmid replication (He et al., 1993; Xu et al., 1993; Xu \& Cohen, 1995) and the destabilization of $r p s O \mathrm{mRNA}$ (Hajnsdorf $e t$ al., 1995). It is possible that the two E. coli PAPs specialize in the polyadenylation of different classes of mRNA, perhaps with some overlap in specificity, or that the enzymes differ in their preference for poly(A) chain initiation and elongation. The examination of the phenotype of E. coli mutants with defects in either or both of the PAP genes should help in resolving these uncertainties.

\section{Concluding remarks}

In spite of its initial neglect, the field of bacterial mRNA polyadenylation is making rapid progress and is beginning to uncover aspects of bacterial RNA metabolism that had not been anticipated. The recent definition of bacterial mRNA polyadenylation on the molecular and genetic levels summarized in this review provided the impetus for the recent advances in the field by demonstrating that the evolution of mRNA polyadenylation predates the emergence of eukaryotes and is therefore a respectable subject for investigation. Although the study of bacterial mRNA polyadenylation is still in its infancy, the possibility of genetic analysis promises rapid advances, and it is not unreasonable to anticipate that the role of mRNA polyadenylation in bacteria will have become clear long before the enormous complexities of eukaryotic poly(A) RNA have been sorted out. Indeed it is quite possible that the lessons learned from the study of bacterial RNA polyadenylation may pave the way for future advances in the eukaryotic field.

\section{Acknowledgements}

This work was supported by Grant R01 GM26517 from the National Institute of General Medical Sciences. I thank Dr Henry Paulus for stimulating discussions and critical reading of the manuscript.

\section{References}

Arraiano, C. M., Yancey, S. D. \& Kushner, S. R. (1988). Stabilization of discrete mRNA breakdown products in ams pnp $r n b$ multiple mutants of Eschericbia coli K-12. J Bacteriol 170, 4625-4633.

August, J. T., Ortiz, P. J. \& Hurwitz, J. (1962). Ribonucleic aciddependent ribonucleotide incorporation. I. Purification and properties of the enzyme. J Biol Chem 237, 3786-3793.

Brown, J. W. \& Reeve, J. N. (1985). Polyadenylated, noncapped RNA from the archaebacterium Methanococcus vannielii. $J$ Bacteriol 162, 909-917.

Cao, G.-j. \& Sarkar, N. (1992a). Poly(A) RNA in Escherichia coli: nucleotide sequence at the junction of the $l p p$ transcript and the polyadenylate moiety. Proc Natl Acad Sci US $A$ 89, 7546-7550.

Cao, G.-j. \& Sarkar, N. (1992b). Identification of the gene for an Escherichia coli poly(A) polymerase. Proc Natl Acad Sci USA 89, 10380-10384.

Cao, G.-j. \& Sarkar, N. (1993). Poly(A) RNA in Bacillus subtilis: 
identification of the polyadenylylation site of flagellin mRNA. FEMS Microbiol Lett 108, 281-286.

Cao, G.-j., Pogliano, J. \& Sarkar N. (1996). Identification of the coding region for a second poly(A) polymerase in Escherichia coli. Proc Natl Acad Sci USA 93 (in press).

Carpousis, A. J., Van Houwe, G., Ehretsmann, C. \& Krisch, H. M. (1994). Copurification of E. coli RNase $E$ and PNPase: evidence for a specific association between two enzymes important in RNA processing and degradation. Cell 76, 889-900.

Chaney, S. G. \& Boyer, P. D. (1972). Incorporation of water oxygens into intracellular nucleotides and RNA. II. Predominantly hydrolytic RNA turnover in Eschericbia coli. J Mol Biol 64, 581-591.

Coburn, G. A. \& Mackie, G. A. (1996). Overexpression, purification, and properties of Escherichia coli ribonuclease II. J Biol Chem 271, 1048-1053.

Cohen, S. N. (1995). Surprises at the $3^{\prime}$ end of prokaryotic RNA. Cell 80, 829-832.

Darnell, J. E., Wall, R. \& Tushinski, R. J. (1971). An adenylic acidrich sequence in messenger RNA of $\mathrm{HeLa}$ cells and its possible relationship to reiterated sites in DNA. Proc Natl Acad Sci USA 68, 13321-13325.

Deutscher, M. P. \& Reuven, N. B. (1991). Enzymatic basis for hydrolytic versus phosphorolytic mRNA degradation in Escbericbia coli and Bacillus subtilis. Proc Natl Acad Sci US A 88, 3277-3280.

Donovan, W. P. \& Kushner, S. R. (1986). Polynucleotide phosphorylase and ribonuclease II are required for cell viability and mRNA turnover in Eschericbia coli K-12. Proc Natl Acad Sci USA 83, 120-124.

Duffy, J. J., Chaney, S. G. \& Boyer, P. D. (1972). Incorporation of water oxygens into intracellular nucleotides and RNA. I. Predominantly non-hydrolytic RNA turnover in Bacillus subtilis. J Mol Biol 64, 565-579.

Edmonds, M., Vaughan, M. H., Jr \& Nakazato, H. (1971). Polyadenylic acid sequences in the heterogeneous nuclear RNA and rapidly labeled polyribosomal RNA of HeLa cells: possible evidence for a precursor relationship. Proc Natl Acad Sci USA 68, 1336-1340.

Ehretsmann, C. P., Carpousis, A. J. \& Krisch, H. M. (1992). mRNA degradation in procaryotes. FASEB J 6, 3186-3192.

Fleischmann, R. D., Adams, M. D., White, O. \& 37 other authors. (1995). Whole genome random sequencing of Haemophilus influenqae Rd. Science 269, 496-512.

Fraser, C. M., Gocayne, J. D., White, O. \& 26 other authors. (1995). The minimal gene complement of Mycoplasma genitalium. Science 270, 397-403.

Gershon, P. D., Ahn, B.-Y., Garfield, M. \& Moss, B. (1991). Poly(A) polymerase and a dissociable polyadenylation stimulatory factor encoded by vaccinia virus. Cell 66, 1269-1278.

Gopalakrishna, Y. \& Sarkar, N. (1981). Selective resistance of bacterial polyadenylate-containing RNA to hydrolysis by the guanosine 3',5'-monophosphate-sensitive nuclease of Bacillus brevis. Biochem Biophys Res Commun 103, 454-460.

Gopalakrishna, Y. \& Sarkar, N. (1982a). Characterization of polyadenylate-containing ribonucleic acid from Bacillus subtilis. Biocbemistry 21, 2724-2729.

Gopalakrishna, Y. \& Sarkar, N. (1982b). The synthesis of DNA complementary to polyadenylate-containing RNA from Bacillus subtilis. J Biol Chem 257, 2747-2750.

Gopalakrishna, Y. \& Sarkar, N. (1983). Synthesis of polyadenylatecontaining RNA in vitro in permeable cells of Eschericbia coli B. Arch Biochem Biopbys 224, 196-205.
Gopalakrishna, Y., Langley, D. \& Sarkar, N. (1981). Detection of high levels of polyadenylate-containing RNA in bacteria by the use of a single-step RNA isolation procedure. Nucleic Acids Res 9, 3545-3554.

Guarneros, G. \& Portier, C. (1990). Different specificities of ribonuclease II and polynucleotide phosphorylase in $3^{\prime} \mathrm{mRNA}$ decay. Biocbimie 72, 771-777.

Hajnsdorf, E., Steier, O., Coscoy, L., Teysset, L. \& Régnier, P. (1994). Roles of RNase E, RNase II and PNPase in the degradation of the $r p s O$ transcripts of Escherichia coli: stabilizing function of RNase II and evidence for efficient degradation in an ams pnp rnb mutant. EMBO J 13, 3368-3377.

Hajnsdorf, E., Braun, F., Haugel-Nielsen, J. \& Régnier, P. (1995). Polyadenylylation destabilizes the $r p s \mathrm{O} \mathrm{mRN}$ of Eschericbia coli. Proc Natl Acad Sci USA 92, 3973-3977.

He, L., Søderbom, F., Wagner, E. G. H., Binnie, U., Binns, N. \& Masters, M. (1993). PcnB is required for the rapid degradation of RNAI, the antisense RNA that controls the copy number of ColE1related plasmids. Mol Microbiol 9, 1131-1142.

Hussain, I., Tsukagoshi, N. \& Udaka, S. (1982). Characterization of polyadenylated RNA in a protein-producing bacterium, Bacillus brevis 47. J Bacteriol 151, 1162-1170.

Kalapos, M. P., Cao, G.-j., Kushner, S. R. \& Sarkar, N. (1994). Identification of a second poly(A) polymerase in Escherichia coli. Biochem Biopbys Res Commun 198, 459-465.

Karnik, P., Gopalakrishna, Y. \& Sarkar, N. (1986). Construction of a cDNA library from polyadenylated RNA of Bacillus subtilis and the determination of some 3'-terminal sequences. Gene 49, 161-165. Karnik, P., Taljanidisz, J., Sasvari-Szekely, M. \& Sarkar, N. (1987). 3'-Terminal polyadenylate sequences of Escherichia coli tryptophan synthetase $\alpha$-subunit messenger RNA. J Mol Biol 196, 347-354.

Kaufer, N., Altmann, M. \& Dobren, H. v. (1981). Isolation of highly active polysomes with polyadenylated sequences from Bacillus brevis. FEMS Microbiol Lett 12, 71-75.

Kaur, S. \& Jayaraman, K. (1979). Appearance of polyadenylated RNA species during sporulation in Bacillus polymyxa. Biochem Biophys Res Commun 86, 331-339.

Kelly, K. O. \& Deutscher, M. P. (1992). The presence of only one of five exoribonucleases is sufficient to support the growth of Eschericbia coli. J Bacteriol 174, 6682-6684.

Kerjan, P. \& Szulmajster, J. (1976). Isolation and properties of a cyclic guanosine-monophosphate sensitive intracellular ribonuclease from Bacillus subtilis. Biocbimie 58, 533-541.

Kerjan, P. \& Szulmajster, J. (1980). Isolation and characterization of polyadenylated RNA species from sporulating cells of Bacillus subtilis. Biocbem Biopbys Res Commun 93, 201-208.

Lee, S. Y., Memdecki, J. \& Brawerman, G. (1971). A polynucleotide segment rich in adenylic acid in the rapidly labeled polyribosomal RNA component of mouse sarcoma 180 ascites cells. Proc Natl Acad Sci US A 68, 1331-1335.

Lingner, J., Kellermann, J. \& Keller, W. (1991). Cloning and expression of the essential gene for poly(A) polymerase from $S$. cerevisiae. Nature 354, 496-498.

Liu, J. \& Parkinson, J. S. (1989). Genetics and sequence analysis of the ponB locus, an Escherichia coli gene involved in plasmid copy number control. J Bacteriol 171, 1254-1261.

Liu, J. \& Parkinson, J. S. (1991). Genetic evidence for interaction between the CheW and Tsr proteins during chemoreceptor signaling by Escherichia coli. J Bacteriol 173, 4941-4951.

Lopilato, J., Bortner, S. \& Beckwith, J. (1986). Mutations in a new chromosomal gene of Escherichia coli $\mathrm{K}-12, p c n B$, reduce plasmid 
copy number of pBR322 and its derivatives. Mol Gen Genet 205, 285-290.

McLaren, R. S., Newbury, S. F., Dance, G. S. C., Causton, H. C. \& Higgins, C. F. (1991). mRNA degradation by processive $3^{\prime}-5^{\prime}$ exoribonucleases in vitro and the implications for prokaryotic mRNA decay in vivo. $J$ Mol Biol 221, 81-95.

McLaughlin, C. S., Warner, J. R., Edmonds, M., Nakazato, H. \& Vaughan, M. H. (1973). Polyadenylic acid sequences in yeast messenger ribonucleic acid. J Biol Chem 248, 1466-1471.

Majumdar, P. K. \& McFadden, B. A. (1984). Polyadenylated mRNA from the photosynthetic procaryote Rhodospirillum rubrum. $J$ Bacteriol 157, 795-801.

Marzluff, W. F. \& Pandey, N. B. (1988). Multiple levels of regulation of histone mRNA concentrations. Trends Biocbem Sci 13, 49-52.

Masters, M., March, J. B., Oliver, I. R. \& Collins, J. F. (1990). A possible role for the $p c n B$ gene product of Escbericbia coli in modulating RNA:RNA interactions. Mol Gen Genet 220, 341-344.

Masters, M., Colloms, M. D., Oliver, I. R., He, L., MacNaughton, E. J. \& Charters, Y. (1993). The pcnB gene of Escherichia coli, which is required for ColE1 copy number maintenance, is dispensable. $J$ Bacteriol 175, 4405-4413.

Nakamura, K., Pirtle, R. M., Pirtle, I. M., Takeishi, K. \& Inouye, M. (1980). Messenger ribonucleic acid of the lipoprotein of the Escherichia coli outer membrane. J Biol Chem 255, 210-216.

Nakazato, H., Venkatesan, S. \& Edmonds, M. (1975). Polyadenylic acid sequences in E. coli messenger RNA. Nature 256, 144-146.

O'Hara, E. B., Chekanova, J. A., Ingle, C. A., Kushner, Z. R., Peters, E. \& Kushner, S. R. (1995). Polyadenylylation helps regulate mRNA decay in Escherichia coli. Proc Natl Acad Sci US A 92, 1807-1811.

Ohta, N., Sanders, M. \& Newton, A. (1975). Poly(adenylic acid) sequences in the RNA of Caulobacter crescentus. Proc Natl Acad Sci US A 72, 2343-2346.

Ohta, N., Sanders, M. \& Newton, A. (1978). Characterization of unstable poly(A)-RNA in Caulobacter crescentus. Biocbim Biophys Acta 517, 65-75.

Ono, M. \& Kuwano, M. (1979). A conditional lethal mutation in an Escherichia coli strain with a longer chemical lifetime of mRNA. $J$ Mol Biol 129, 343-357.

Paulus, H. \& Sarkar, N. (1974). Control of transcription in Bacillus brevis by small molecules. In Control of Transcription, pp. 21-34. Edited by B. B. Biswas, R. K. Mandal, A. Stevens \& W. E. Cohn. New York: Plenum.

Pepe, C. M., Maslesa-Galic, S. \& Simons, R. W. (1994). Decay of the IS10 antisense RNA by $3^{\prime}$ exoribonucleases : evidence that RNase II stabilizes RNA-OUT against PNPase attack. Mol Microbiol 13, 1133-1142.

Perry, R. P., Kelley, D. E. \& La Torre, J. (1972). Lack of polyadenylic acid sequences in the messenger RNA of E. coli. Biochem Biophys Res Commun 48, 1593-1600.

Py, B., Causton, H., Mudd, E. A. \& Higgins, C. F. (1994). A protein complex mediating mRNA degradation in Escherichia coli. Mol Microbiol 14, 717-729.

Py, B., Higgins, C. F. H., Krisch, H. M. \& Carpoussis, A. J. (1996). A DEAD-box RNA helicase in the Escberichia coli degradosome. Nature 381, 169-172.

Raabe, T., Bollum, F. J. \& Manley, J. L. (1991). Primary structure and expression of bovine poly(A) polymerase. Nature 353, 229-234.
Ramanarayanan, M. \& Srinivasan, P. R. (1976). Further studies on the isolation and properties of polyriboadenylate polymerase from Eschericbia coli PR7 (RNase I', pnp). J Biol Cbem 251, 6274-6286.

Régnier, P. \& Hajnsdorf, E. (1991). Decay of mRNA encoding ribosomal protein S15 of Escherichia coli is initiated by an RNase Edependent endonucleolytic cleavage that removes the $3^{\prime}$ stabilizing stem and loop structure. J Mol Biol 217, 283-292.

Reuven, N. B. \& Deutscher, M. P. (1993a). Multiple exoribonucleases are required for the $3^{\prime}$ processing of Escherichia coli tRNA precursors in vivo. FASEB J 7, 143-148.

Reuven, N. B. \& Deutscher, M. P. (1993b). Substitution of the $3^{\prime}$ terminal adenosine residue of transfer RNA in vivo. Proc Natl Acad Sci US A 90, 4350-4353.

Sachs, A. (1990). The role of poly(A) in the translation and stability of mRNA. Curr Opin Cell Biol 2, 1092-1098.

Sachs, A. B. \& Deardorff, J. A. (1992). Translation initiation requires the $\mathrm{PAB}$-dependent poly(A) ribonuclease in yeast. Cell 70, 961-973.

Sarkar, N. \& Paulus, H. (1975). A guanosine 3', 5'-monophosphatesensitive nuclease from Bacillus brevis. J Biol Chem 250, 684-690.

Sarkar, N., Langley, D. \& Paulus, H. (1978). Isolation and characterization of polyadenylate-containing RNA from Bacillus brevis. Biochemistry 17, 3468-3474.

Sarkar, N., Cao, G.-j. \& Kalapos, M. P. (1995). Polyadenylation of mRNA in prokaryotes. In Abstracts of the Meeting on Molecular Genetics of Bacteria \& Pbages (August 1995), p. 251. Cold Spring Harbor, NY: Cold Spring Harbor Laboratory.

Schafer, R., Zillig, W. \& Priess, H. (1972). A novel RNA-primed polynucleotidepyrophosphorylase from E. coli. FEBS Lett 25, 87-90.

Schultz, G. A., Chaconas, G. \& Moore, R. L. (1978). Polyadenylic acid sequences in the RNA of Hyphomicrobium. J Bacteriol 133, 569-575.

Sippel, A. E. (1973). Purification and characterization of adenosine phosphate: ribonucleic acid adenyltransferase from Escherichia coli. Eur J Biochem 37, 31-40.

Srinivasan, P. R., Ramanarayanan, M. \& Rabbani, E. (1975). Presence of polyriboadenylate sequences in pulse-labeled RNA of Escherichia coli. Proc Natl Acad Sci US A 72, 2910-2914.

Taljanidisz, J., Karnik, P. \& Sarkar, N. (1987). Messenger ribonucleic acid for the lipoprotein of the Escherichia coli outer membrane is polyadenylated. J Mol Biol 193, 507-515.

Wahle, E. (1991). Purification and characterization of a mammalian polyadenylate polymerase involved in the $3^{\prime}$ end processing of messenger RNA precursors. J Biol Cbem 266, 3131-3139.

Wahle, E., Martin, G., Schiltz, E. \& Keller, W. (1991). Isolation and expression of cDNA clones encoding mammalian poly(A) polymerase. EMBO J 10, 4251-4257.

Wang, W. \& Bechhofer, D. H. (1996). Properties of a Bacillus subtilis polynucleotide phosphorylase deletion strain. $J$ Bacteriol 178, 2375-2382.

Xu, F. \& Cohen, S. N. (1995). RNA degradation in Eschericbia coli regulated by $3^{\prime}$ adenylation and $5^{\prime}$ phosphorylation. Nature 374 , 180-183.

Xu, F., Lin-Chao, S. \& Cohen, S. N. (1993). The Eschericbia coli ponB gene promotes adenylylation of antisense RNAI of ColE1-type plasmids in vivo and degradation of RNAI decay intermediates. Proc Natl Acad Sci USA 90, 6756-6760. 